Commentary Article

\title{
Ever-Evolving landscape of biosimilars in Canada; findings and implications from a global perspective
}

\author{
Brian Godman ${ }^{1,2,3^{*}}$, BSc, PhD, Eleonora Allocati ${ }^{4}$, BSc, MSc, Evelien Moorkens ${ }^{5}$, BSc, MSc \\ ${ }^{1}$ Strathclyde Institute of Pharmacy and Biomedical Sciences, University of Strathclyde, Glasgow G4 \\ ORE, United Kingdom. Email: brian.godman@strath.ac.uk \\ ${ }^{2}$ Division of Public Health Pharmacy and Management, School of Pharmacy, Faculty of Health \\ Sciences, Sefako Makgatho Health Sciences University, Pretoria, South Africa \\ ${ }^{3}$ Department of Laboratory Medicine, Division of Clinical Pharmacology, Karolinska Institutet, \\ Karolinska University Hospital Huddinge, Stockholm, Sweden. Email: Brian.Godman@ki.se \\ ${ }^{4}$ Istituto di Ricerche Farmacologiche 'Mario Negri' IRCCS, Milan, Italy. Email: \\ eleonora.allocati@marionegri.it
}

${ }^{5}$ KU Leuven Department of Pharmaceutical and Pharmacological Sciences, Leuven, Belgium. Email: evelien.moorkens@kuleuven.be

*Author for correspondence: Strathclyde Institute of Pharmacy and Biomedical Sciences, University of Strathclyde, Glasgow G4 ORE, United Kingdom. Email: Brian.godman@strath.ac.uk. Telephone: 0141548 3825. Fax: 01415522562

(Accepted for publication GABI Journal)

Siu et al. have comprehensively assessed the rapidly changing regulation and reimbursement environment for biologicals and biosimilars in Canada and the resultant implications.

Brian Godman, Eleonora Allocati and Evelien Moorkens review the paper by Siu et al. regarding the evolving regulatory and reimbursement landscape in Canada (1), and subsequently link these within the broader global context of biosimilar market access to stimulate future activities and debates in this important area. This includes the current and potential market value of biosimilars, their regulatory and reimbursement environments as well as ongoing initiatives across countries to enhance their utilisation to maximise potential savings. In addition, the potential sustainability of appreciable discounts among both originator and biosimilar manufacturers.

Siu et al. point out that biologics are now commonly prescribed medicines for a wide variety of disease areas including diabetes, immunological diseases such as arthritis, inflammatory bowel disease, and psoriasis, as well as for a number of cancers (1-4). Their high prices coupled with the prevalence of these diseases have resulted in considerable sales. Worldwide sales of cancer medicines, many of which are biologicals, was US\$107billion in 2015 and rising $(5,6)$. The global anti TNF market was valued at US $\$ 40.4$ billion in 2017 , and expected to expand at $2.54 \%$ per year with Europe and the US currently accounting for $87.7 \%$ of sales (7). Within this, worldwide sales of adalimumab were US\$ 17.6 billion in 2017, rising to nearly US $\$ 20$ million in 2018 thereby making it the world's best selling medicine, with infliximab sales at US $\$ 5.9$ billion in 2017 and etanercept at US $\$ 5.8$ billion in $2017(8,9)$. In Canada in 2017, biologicals accounted for $21.6 \%$ of overall public healthcare expenditure with the anti-TNF medicines accounting for $8.2 \%$ of total expenditure (1). This compares with the US where biologicals currently account for $37 \%$ of net drug spending (10). In the UK, anti-TNF medicines are also one of the highest spend areas within high cost medicines, with GB£780 million spent in England in 2018 (11), and in Germany, adalimumab was the top selling medicine in 2017 with net costs to the statutory health insurance system of $€ 975$ million (12). Consequently, the introduction of biosimilars, especially in oncology and immunological diseases, should be of considerable interest to payers of healthcare and patients world-wide. We have seen limited use to date of biological medicines in many Central and Eastern European countries versus Western European countries due to their high costs and co-payments (13-15). Consequently, biosimilars should help address this as prices fall. A competitive market should also bring down the cost of biosimilar insulins, helping many patients in low and middle income countries currently denied such treatments (16).

As a result of the current and envisaged sales of biological medicines coupled with ongoing initiatives, we are seeing considerable growth in the availability and use of biosimilars especially in China and 
Europe (17-20). This will help increase their world-wide sales from approximately US $\$ 4$ billion in 2018 (21). Competition, with the resultant impact on overall expenditures, should intensify as many biological medicines that are currently used first or second line in treatment regimens lose their patent benefitting patients and payers (22).

Siu et al. point out appreciable changes in the regulatory and HTA domains in the biosimilar environment in Canada in recent years to enhance their availability and promote their uptake (1). This includes Health Canada in 2015 launching a pilot programme to provide manufacturers with the ability to discuss their biosimilar with Health Canada. In 2017, Health Canada laid out a Regulatory Review of Drugs and Devices which included a project to improve access to biologics (biosimilars and nonbiosimilars) by increasing their regulatory review capacity (1). This should result in a more secure supply of biologic drugs and more affordable biologics. In addition, Health Canada and HTA organisations in Canada as well as INESS in Quebec began collaborating in 2018 to better align review processes including biosimilars to reduce duplication and time lags between regulatory approval and reimbursement (1). Heath Canada also intends to implement an updated naming convention for biologics including the product's brand name, International non-proprietary name (INN), and the Drug Identification number (DIN), to support a clear distinction between biologics including biosimilars to enhance adverse event tracking (1). There have also been initiatives in other countries to enhance earlier access to biosimilars $(20,21,23-26)$ although further developments are being proposed (27). Interestingly, whilst modifications to the manufacturing process of originator biologic drugs are common, regulators have very rarely required clinical studies to assess similarities even in the case of major manufacturing changes $(28,29)$.

With respect to reimbursing biosimilars, a number of significant changes have taken place recently in Canada to ease the situation. In Canada, the CADTH (Canadian Agency for Drugs and Technologies in Health) Common Drug Review (CDR) plays an important role in deciding whether medicines will be eligible for public reimbursement, with the Provinces subsequently typically making the final decision based on CDR recommendations (30). In May 2019, CADTH announced that as of June 1, 2019, it would no longer routinely review biosimilars via its CDR and pCODR (pan-Canadian Oncology Drug Review) programmes to streamline access (1). A similar situation is seen in Quebec with INESS. The pan-Canadian Pharmaceutical Alliance (pCPA) subsequently uses its combined purchasing power to improve access and increase the cost-effectiveness of medicines, similar to cross country collaborations in Europe (31-34). In 2016, pCPA launched a more comprehensive biosimilar policy and in 2018 released a Biologics Policy Directive in which biologic drugs for which biosimilars are already reimbursed as well as any new biosimilar will not be considered for reimbursement unless there are transparent price reductions to the lowest list price, providing an exemplar to others (1). In addition, the potential for tiered pricing in certain therapeutic areas, which is likely to lead to increasing discounts as more biosimilars are launched. Manitoba was the first Canadian Province to instigate tiered arrangements in which biologic-naive patients must first be prescribed a biosimilar or an approved biologic where no biosimilar exists (1). Private Insurers in Canada are also now offering preferential coverage for biosimilars leading to average savings of CAD $\$ 8,500$ per participating member per year (1). Such initiatives should help boost the use of biosimilars in Canada along with educational, awareness and other initiatives, with biosimilar use currently lagging behind Europe (1, 19).

Biosimilars Canada has also recently developed a centralised patient support service platform to assist manufacturers and patients (1). Policies regarding switching should also help enhance the use of biosimilars in Canada along with collecting real-world evidence to help ally current fears (1). There have been considerable concerns with patients being switched between an originator biological medicine and a biosimilar across countries as well as indication extrapolation especially with respect to the risk of immunogenicity-related safety issues and diminished efficacy $(17,35)$. However, an appreciable number of studies have now shown that such risks are unchanged when switching between an originator and a biosimilar (11, 21, 36-44). As a result, patient and physician organisations in Canada are now supporting non-medical switching (1), similar to initiatives among European countries such as France (45). The growing body of evidence for biosimilars is also leading to suggestions to modify the current lengthy approval process and costs to enhance earlier access and strengthen competition (46). There are though still concerns with switching among physicians that need to be addressed with education as these can negatively impact on their future utilisation (47-49). Additional monitoring of patient outcomes in routine clinical practice should help further reduce 
possible concerns as well as potentially reduce the need for comparative clinical efficacy evidence as more originators lose their patents. This should reduce the investment needed for developing new biosimilars, and combined with developments in manufacturing (50), should help reduce future prices.

A number of other initiatives have also recently been undertaken in Canada to enhance the utilisation of biosimilars. This includes the pan-Canadian Oncology Biosimilars Initiative to enhance successful adoption of biosimilars in oncology. British Columbia launched its Biosimilars Initiative in May 2019 promoting switching, with the savings used to lower premiums and co-pays where pertinent (1). Other Provinces are likely to follow.

We have also seen initiatives among other countries to enhance the use of biosimilars. Moorkens et al. and Vogler et al. have summarised these for Europe as well as provided future guidance to further enhance their uptake $(51,52)$. More recently, Simoens et al. gave guidance on additional measures that could be introduced in Europe to fully realise the potential of biosimilars (53). We are also seeing prescribing targets for biosimilars among European countries including national frameworks (54-57). However, there are still limited initiatives in some countries including Japan where currently no position statement regarding biosimilars has been included in treatment guidelines for any of the cancer societies (58). This may change though with increasing pressure on resources and with the Japanese government now reviewing supportive measures for biosimilars (58). Smeeding et al. recently highlighted a number of issues that payers in the US should consider as part of any strategy to increase the use of biosimilars (59).

Ongoing initiatives across countries, including both supply-side and demand-side measures, have increased potential savings from biosimilars. Siu et al. suggest that by the third year of entry, potential savings from biosimilars in Canada could range from $13-43 \%$ for acute use products such as Granulocyte Colony-stimulating Factors (G-CSF) and erythropoietin (EPO) and 8-43\% for chronic-use products, e.g. anti-TNFs (1). This is helped by price reductions for biosimilars in Canada ranging between $17 \%$ and $50 \%$ from the originator.

A number of European countries have introduced price-link policies for biosimilars to lower their prices and enhance savings, with other countries instigating measures such as tendering to lower prices (52, $60,61)$. For instance, tendering among hospitals in Norway resulted in a $72 \%$ discount compared to its list (60), and tendering in the UK will result in GB£300million (approximately $\$ 386$ million) savings from currently GB£400 million-per-year (approximately $\$ 514$ million) spent on adalimumab (62). In Germany, the current high use of adalimumab and anticipated savings resulted in biosimilars accounting for $28 \%$ of total prescriptions of adalimumab within eight weeks of launch (12). In the US, it is estimated that biosimilars will reduce direct spending on biologic drugs by $\$ 54$ billion from 2017 to $2026(10,63)$; with savings likely to be higher with greater discounts than $20 \%$ to $30 \%$ currently seen (10). Substantial discounts for biosimilars across Europe, greater than initial considerations (61), coupled with demand-side measures, have already resulted in their appreciably increased use in recent years. In some cases and countries in Europe, biosimilars now account for the total market, e.g. EPO and G-CSF, providing guidance to others (19).

However, there are concerns that originators are starting to substantially lower their prices potentially affecting future biosimilar availability and the sustainability of the market place as seen recently with adalimumab $(9,19,64)$. In addition, we are seeing originator companies defending manufacturing and other patents, as well as seeking to instigate hurdles in the US making it more difficult for insurers to place biosimilars on formularies in order to disrupt the biosimilar market $(10,65,66)$. Originator companies are also developing new formulations of their biologicals to try and further disrupt the biosimilar market building on previous evergreening tactics $(19,67)$. There are also suggestions to lower the prices of originators in countries such as Belgium and the US over time, negating the need for biosimilars to further interfere with this market (68). We will continue to monitor these developments and their implications.

In conclusion, Siu et al. have provided a comprehensive review of current and planned policies in Canada to enhance the use of biosimilars at competitive prices to benefit payers and patients. This is important for disease areas such as cancer with ever increasing prices for new medicines, which potentially threaten the sustainability of healthcare systems $(69,70)$. It is also increasingly likely that health authorities will start re-assessing prices and potential discounts for on-patent medicines for 
oncology and immunological diseases as more standard medicines used for pricing negotiations lose their patents $(6,71)$. Siu et al. also remind key stakeholders to continually monitor developments with biosimilars including both supply- and demand-side initiatives as well as encourage countries to learn from each other to enhance their uptake. This is critical for health authorities with the instigation of disruptive tactics such as in the Netherlands with AbbVie and in the US with hurdles such as rebates and other strategies with insurers to limit biosimilar use. In addition, payers need to monitor the development of new formulations by originator manufacturers and plan for the implications.

\section{Funding}

There was no funding for this commentary paper.

\section{Conflicts of interest}

The authors have no conflicts of interest to declare.

\section{References}

1. Siu ECK, Tomalin A, West K, Anderson S, Wyatt G. An Ever-Evolving Landscape: an Update on the Rapidly Changing Regulation and Reimbursement of Biosimilars in Canada. Generics and Biosimilars Journal (GaBI) 2019 (In Press).

2. Ferro A, Boyce M. Biological therapies: a long way on from Jenner. British journal of clinical pharmacology. 2013;76(2):161-3.

3. Barker J, Girolomoni G, Egeberg A, Goncalves J, Pieper B, Kang T. Anti-TNF biosimilars in psoriasis: from scientific evidence to real-world experience. The Journal of dermatological treatment. 2019:1-7.

4. Kuenzig ME, Benchimol El, Lee L, Targownik LE, Singh H, Kaplan GG, et al. The Impact of Inflammatory Bowel Disease in Canada 2018: Direct Costs and Health Services Utilization. Journal of the Canadian Association of Gastroenterology. 2019;2(Suppl 1):S17-s33.

5. IMS Institute for Healthcare Informatics. Global Oncology Trend Report. A Review of 2015 and Outlook to 2020. June 2016. Available at URL:

https://www.scribd.com/document/323179495/IMSH-Institute-Global-Oncology-Trend-2015-2020Report.

6. Godman B, Bucsics A, Vella Bonanno P, Oortwijn W, Rothe CC, Ferrario A, et al. Barriers for Access to New Medicines: Searching for the Balance Between Rising Costs and Limited Budgets. Front Public Health. 2018;6:328.

7. Transparency Market Research. Global TNF Inhibitors Market - Snapshot. 2018. Available at URL: https://www.transparencymarketresearch.com/tnf-inhibitors-market.html.

8. $\quad$ PRNewswire. Global Tumor Necrosis Factor Inhibitors Drug Market, Dosage, Price \& Clinical Pipeline Outlook 2024. 2018. Available at URL: https://www.prnewswire.com/news-releases/tumornecrosis-factor-inhibitors-drug-market-2024---humira-and-remicade-have-made-it-to-the-list-ofblockbuster-drugs-of-2017-with-global-sales-of-us-176-billion-300615283.html.

9. Hoen E't. Humiragate: AbbVie's desperate attempts to keep its monopoly. 2019. Available at URL: https://medicineslawandpolicy.org/2019/03/humiragate-abbvies-desperate-attempts-to-keep-itsmonopoly/.

10. Stiff KM, Cline A, Feldman SR. Tracking the price of existing biologics when drugs enter the market. Expert review of pharmacoeconomics \& outcomes research. 2019;19(4):375-7.

11. Chan A, Kitchen J, Scott A, Pollock D, Marshall R, Herdman L. Implementing and delivering a successful biosimilar switch programme - the Berkshire West experience. Future healthcare journal. 2019;6(2):143-5.

12. Grubert N. Biosimilar adalimumab achieves record launch impact in Germany-but government still plans reforms to boost biosimilar usage. Available at URL:

https://www.linkedin.com/pulse/biosimilar-adalimumab-achieves-record-launch-impact-still-grubert/. 13. Baumgart DC, Misery L, Naeyaert S, Taylor PC. Biological Therapies in Immune-Mediated Inflammatory Diseases: Can Biosimilars Reduce Access Inequities? Frontiers in pharmacology. 2019;10:279.

14. Putrik P, Ramiro S, Kvien TK, Sokka T, Pavlova M, Uhlig T, et al. Inequities in access to biologic and synthetic DMARDs across 46 European countries. Annals of the rheumatic diseases. 2014;73(1):198-206.

15. Kostic M, Djakovic L, Sujic R, Godman B, Jankovic SM. Inflammatory Bowel Diseases (Crohn s Disease and Ulcerative Colitis): Cost of Treatment in Serbia and the Implications. Applied health economics and health policy. 2017;15(1):85-93. 
16. Gotham D, Barber MJ, Hill A. Production costs and potential prices for biosimilars of human insulin and insulin analogues. BMJ global health. 2018;3(5):e000850.

17. O'Callaghan J, Barry SP, Bermingham M, Morris JM, Griffin BT. Regulation of biosimilar medicines and current perspectives on interchangeability and policy. European journal of clinical pharmacology. 2019;75(1):1-11.

18. Migliavacca Zucchetti B, Nicolo E, Curigliano G. Biosimilars for breast cancer. Expert opinion on biological therapy. 2019:1-7.

19. IQVIA Report 2018: The impact of biosimilar competition in Europe. Available at URL: https://ec.europa.eu/docsroom/documents/31642

20. Derbyshire M. Regulation of copy biologicals in China. Generics and Biosimilars Initiative Journal (GaBI Journal). 2018;7(2):75-6.

21. Shina S. Pharma News. Top developments in biosimilars during 2018. Generics and Biosimilars Initiative Journal (GaBI) 2019; 8 (1): 32-9.

22. Derbyshire M, Shina S. Patent expiry dates for biologicals: 2017 update. Generics and Biosimilars Initiative Journal (GaBI Journal). 2018;7(1):29-34.

23. US Food and Drug Administration. Biosimilar Product Regulatory Review and Approval. Available at URL: https://www.fda.gov/media/108621/download.

24. US Food and Drug Administration. Biosimilar Product Information. 2019. Available at URL: https://www.fda.gov/drugs/biosimilars/biosimilar-product-information.

25. Pettit C. Biosimilars Market Is Ripe for Cost Savings. 2019. Available at URL:

https://www.centerforbiosimilars.com/contributor/chad-pettit/2019/06/biosimilars-market-is-ripe-forcost-savings.

26. European Medicines Agency. Guideline on similar biological medicinal products. 2014.

Available at URL: https://www.ema.europa.eu/en/documents/scientific-guideline/guideline-similarbiological-medicinal-products-rev1_en.pdf.

27. Niazi SK. Rationalizing FDA guidance on biosimilars - expediting approvals and acceptance. Generics and Biosimilars Initiative Journal (GaBI Journal). 2018;7(2):84-91.

28. Jimenez-Pichardo L, Gazquez-Perez R, Sierra-Sanchez JF. Degree of prescriber's knowledge about variability in biological drugs "innovators" in manufacturing process. European journal of clinical pharmacology. 2018;74(4):505-11.

29. Vezer B, Buzas Z, Sebeszta M, Zrubka Z. Authorized manufacturing changes for therapeutic monoclonal antibodies (mAbs) in European Public Assessment Report (EPAR) documents. Current medical research and opinion. 2016;32(5):829-34.

30. CADTH Common Drug Review (CDR). 2019. Available at URL: https://www.cadth.ca/aboutcadth/what-we-do/products-services/cdr.

31. Press Release. Ireland to open negotiations with Belgium, the Netherlands, Luxembourg and Austria on drug pricing and supply - Minister Harris. Available at URL: http://health.gov.ie/blog/pressrelease/ireland-to-open-negotiations-with-belgium-the-netherlands-luxembourg-and-austria-on-drugpricing-and-supply-minister-harris/.

32. European Observatory. How can voluntary cross-border collaboration in public procurement improve access to health technologies in Europe? Available at URL:

http://www.euro.who.int/_data/assets/pdf_file/0009/331992/PB21.pdf?ua=1.

33. Henrard S, Arickx F. Negotiating prices of drugs for rare diseases. Bull World Health Organ. 2016;94(10):779-81.

34. O'Mahony JF. Beneluxa: What are the Prospects for Collective Bargaining on Pharmaceutical Prices Given Diverse Health Technology Assessment Processes? PharmacoEconomics.

2019;37(5):627-30.

35. Aladul MI, Fitzpatrick RW, Chapman SR. Healthcare professionals' perceptions and perspectives on biosimilar medicines and the barriers and facilitators to their prescribing in UK: a qualitative study. BMJ open. 2018;8(11):e023603.

36. Cohen HP, Blauvelt A, Rifkin RM, Danese S, Gokhale SB, Woollett G. Switching Reference Medicines to Biosimilars: A Systematic Literature Review of Clinical Outcomes. Drugs.

2018;78(4):463-78.

37. Gisondi P, Bianchi L, Calzavara-Pinton P, Conti A, Chiricozzi A, Fimiani M, et al. Etanercept biosimilar SB4 in the treatment of chronic plaque psoriasis: data from the Psobiosimilars registry. The British journal of dermatology. 2019;180(2):409-10.

38. Jorgensen KK, Olsen IC, Goll GL, Lorentzen M, Bolstad N, Haavardsholm EA, et al. Switching from originator infliximab to biosimilar CT-P13 compared with maintained treatment with originator infliximab (NOR-SWITCH): a 52-week, randomised, double-blind, non-inferiority trial.

Lancet. 2017;389(10086):2304-16. 
39. Stebbing J, Baranau YV, Baryash V, Manikhas A, Moiseyenko V, Dzagnidze G, et al. Doubleblind, randomized phase III study to compare the efficacy and safety of CT-P6, trastuzumab biosimilar candidate versus trastuzumab as neoadjuvant treatment in HER2 positive early breast cancer (EBC). Journal of Clinical Oncology. 2017;35(15_suppl):510-.

40. Esteva FJ, Stebbing J, Wood-Horrall RN, Winkle PJ, Lee SY, Lee SJ. A randomised trial comparing the pharmacokinetics and safety of the biosimilar CT-P6 with reference trastuzumab. Cancer chemotherapy and pharmacology. 2018;81(3):505-14.

41. Komaki Y, Yamada A, Komaki F, Micic D, Ido A, Sakuraba A. Systematic review with metaanalysis: the efficacy and safety of CT-P13, a biosimilar of anti-tumour necrosis factor-alpha agent (infliximab), in inflammatory bowel diseases. Alimentary pharmacology \& therapeutics.

2017;45(8):1043-57.

42. Pegram MD, Bondarenko I, Zorzetto MMC, Hingmire S, Iwase H, Krivorotko PV, et al. PF05280014 (a trastuzumab biosimilar) plus paclitaxel compared with reference trastuzumab plus paclitaxel for HER2-positive metastatic breast cancer: a randomised, double-blind study. $\mathrm{Br} \mathrm{J}$ Cancer. 2019;120(2):172-82.

43. Waller CF, Ranganna GM, Pennella EJ, Blakeley C, Bronchud MH, Mattano LA, Jr., et al. Randomized phase 3 efficacy and safety trial of proposed pegfilgrastim biosimilar MYL-1401H in the prophylactic treatment of chemotherapy-induced neutropenia. Ann Hematol. 2019;98(5):1217-24. 44. Tweehuysen L, Huiskes VJB, van den Bemt BJF, Vriezekolk JE, Teerenstra S, van den Hoogen FHJ, et al. Open-Label, Non-Mandatory Transitioning From Originator Etanercept to Biosimilar SB4: Six-Month Results From a Controlled Cohort Study. Arthritis \& rheumatology. 2018;70(9):1408-18.

45. GABI Journal. Policies \& Legislation - France aims to reach $80 \%$ biosimilar penetration by 2022. 2018. Available at URL: http://gabionline.net/Policies-Legislation/France-aims-to-reach-80biosimilar-penetration-by-2022

46. Frapaise FX. The End of Phase 3 Clinical Trials in Biosimilars Development? BioDrugs : clinical immunotherapeutics, biopharmaceuticals and gene therapy. 2018;32(4):319-24.

47. Teeple A, Ellis LA, Huff L, Reynolds C, Ginsburg S, Howard L, et al. Physician attitudes about non-medical switching to biosimilars: results from an online physician survey in the United States. Current medical research and opinion. 2019;35(4):611-7.

48. Pineles D, Malter L, Liang PS, Arsuaga A, Bosworth B, Hudesman DP, et al. The nocebo effect and patient perceptions of biosimilars in inflammatory bowel disease. European journal of clinical pharmacology. 2018;74(10):1361-2.

49. Smolen JS, Goncalves J, Quinn M, Benedetti F, Lee JY. Era of biosimilars in rheumatology: reshaping the healthcare environment. RMD open. 2019;5(1):e000900.

50. DiMasi JA, Smith Z, Getz KA. Assessing the Financial Benefits of Faster Development Times: The Case of Single-source Versus Multi-vendor Outsourced Biopharmaceutical Manufacturing. Clinical therapeutics. 2018;40(6):963-72.

51. Moorkens E, Vulto AG, Huys I, Dylst P, Godman B, Keuerleber S, et al. Policies for biosimilar uptake in Europe: An overview. PloS one. 2017;12(12):e0190147.

52. Vogler S, Schneider P. Do pricing and usage-enhancing policies differ between biosimilars and generics? Findings from an international survey. Generics and Biosimilars Initiative Journal (GaBI Journal). 2017;6(2):79-88.

53. Simoens S, Le Pen C, Boone N, Breedveld N, Llombart-Cussac A, Jorgensen F et al. How to realize the potential of off-patent biologicals and biosimilars in Europe? Guidance to policymakers.

Generics and Biosimilars Initiative Journal (GaBI Journal). 2018;7(2):70-4.

54. Health Improvement Scotland (NHS Scotland). Biosimilar Medicines: A National Prescribing Framework. 2018. Available at URL: file:///C:/Users/mail/Downloads/20180309-Biosimilar-medicinesMar18-final\%20(1).pdf.

55. All Wales Medicine Strategy Group. National Prescribing Indicators 2018-2019. 2018.

Available at URL:

http://www.awmsg.org/docs/awmsg/medman/National\%20Prescribing\%20Indicators\%2020182019.pdf.

56. NHS Scotland. Secondary Care National Therapeutic Indicators 2018/19. Available at URL: https://www.therapeutics.scot.nhs.uk/wp-content/uploads/2018/08/Secondary-Care-NationalTherapeutic-Indicators-Version-1.0.pdf.

57. Underwood G. The biosimilars era. Pharma Times 2018. Available at URL: http://www.pharmatimes.com/magazine/2018/june_2018/the_biosimilars_era.

58. Hara F, Tajima K, Tanabe K. Current situation and challenges regarding biosimilars in Japan: an example of trastuzumab biosimilars for breast cancer. Future oncology. 2019;15(12):1353-61. 
59. Smeeding J, Malone DC, Ramchandani M, Stolshek B, Green L, Schneider P. Biosimilars: Considerations for Payers. P \& T : a peer-reviewed journal for formulary management. 2019;44(2):5463.

60. Matusewicz W, Godman B, Pedersen HB, Furst J, Gulbinovic J, Mack A, et al. Improving the managed introduction of new medicines: sharing experiences to aid authorities across Europe. Expert review of pharmacoeconomics \& outcomes research. 2015;15(5):755-8.

61. Godman B. Health authority perspective on biosimilars. GaBI Journal. 2013;2(1):10-1.

62. Davio K. After Biosimilar Deals, UK Spending on Adalimumab Will Drop by $75 \% .2018$.

Available at URL: https://www.centerforbiosimilars.com/news/after-biosimilar-deals-uk-spending-onadalimumab-will-drop-by-75.

63. Mulcahy AW, Hlavka JP, Case SR. Biosimilar Cost Savings in the United States: Initial Experience and Future Potential. Rand health quarterly. 2018;7(4):3.

64. Sagonowsky E. AbbVie's massive Humira discounts are stifling Netherlands biosimilars: report. 2019. Available at URL: https://www.fiercepharma.com/pharma/abbvie-stifling-humira-biosimcompetition-massive-discounting-dutch-report.

65. Reinke T. Show Us (the U.S.) the Savings. Managed care. 2019;28(1):9-10.

66. Kellaher C. AbbVie, Boehringer Settle U.S. Patent Dispute Over Drug Humira. 2019.

Available at URL: https://www.wsj.com/articles/abbvie-boehringer-settle-u-s-patent-dispute-over-drughumira-11557851079.

67. Vernaz N, Haller G, Girardin F, Huttner B, Combescure C, Dayer P, et al. Patented drug extension strategies on healthcare spending: a cost-evaluation analysis. PLoS Med.

2013;10(6):e1001460.

68. Atteberry P, Bach PB, Ohn JA, Trusheim M. Biologics Are Natural Monopolies (Part 1): Why Biosimilars Do Not Create Effective Competition. Health Affairs Blog. 2019. Available at URL: https://www.healthaffairs.org/do/10.1377/hblog20190405.396631/full/.

69. Godman B, Wild C, Haycox A. Patent expiry and costs for anti-cancer medicines for clinical use. Generics and Biosimilars Initiative Journal 2017;6(3):105-6.

70. Ghinea H KI, Lipworth W. If we don't talk about value, cancer drugs will become terminal for health systems. Available at URL: http://theconversation.com/if-we-dont-talk-about-value-cancerdrugs-will-become-terminal-for-health-systems-44072

71. Godman B, Hill A, Simoens S, Kurdi A, Gulbinovič J, Martin AP. Pricing of oral generic cancer medicines in Europe; findings and implications. GABI Journal. 2019. Eprint. Available at URL: http://gabi-journal.net/pricing-of-oral-generic-cancer-medicines-in-europe-findings-andimplications.html. 